\title{
Adaptive and Behavioral Development in Children with Down Syndrome at School Age with Special Emphasis on Attention Deficit Hyperactivity Disorder (ADHD)
}

\author{
Asher Ornoy ${ }^{1}$, Tanya Rihtman ${ }^{2}$ and Shula Parush ${ }^{2}$ \\ ${ }^{1}$ Israel Canada Institute for Medical Research, Hebrew University Hadassah Medical \\ School and Israeli Ministry of Health, Jerusalem \\ ${ }^{2}$ School of Occupational Therapy, \\ Hebrew University Hadassah Medical School, Jerusalem,
}

Israel

\section{Introduction}

Down syndrome (DS) is the most common chromosomal anomaly occurring in live births (Capone et al, 2004; Menkes \& Falk, 2005) and it has been described as a syndrome-complex of genetic origin with protean neurobiological consequences, and several characteristic neurodevelopmental and neuropsychological manifestations. Down syndrome is also considered to be the most common single cause of mild, moderate and severe mental retardation (MR) with over half of individuals with DS attaining an IQ of between 50 and 25 by the end of the first decade of life (Bittles \& Glasson, 2004; Capone, 2004; Hanson, 2003; Menkes \& Falk, 2005; Roubertoux \& Kerdelhue, 2006; Van Cleve \& Cohen, 2006; Vicari, 2006). Individuals with Down syndrome experience a reduced life expectancy, but within the DS population, life expectancy is increasing.

Clinically, individuals with Down syndrome have typical physical and anatomical characteristics (Van Cleve \&, Cohen, 2006). An issue of major medical importance is the participation and function on the health of individuals, communities and society. A holistic approach is now vital when assessing the individual, from body functions and IQ to learning abilities, attentional skills, daily activities and participation defined by the ICF as 'the execution of a task or action' with involvement in a life situation (WHO, 2001). Despite these shifts, there is limited investigation into the activity performance, participation, learning and behavior of children with DS, as measured by their adaptive functioning.

The cognitive limitations of individuals with Down syndrome have an important influence on the level of functioning attained and a significant correlation between IQ and all areas of function has been noted. Relatively preserved visual-spatial and visual-motor skills are often noted, yet the influence of these skills on the activity performance of the child with DS is unclear (Fiddler, et al 2005; Vicari 2006; Vicari \& Carlesimo 2006). 
The few existing studies investigating the holistic functional profile of children with DS have tended to be qualitative and investigated adult populations, even though all these children will display some form of intellectual disability requiring functional intervention. Few studies have measured specific skills appropriate to the wide range of abilities presented by children with Down syndrome or reported attainment levels for children in different age groups (Turner \& Alborz 2003). There remains, therefore, a dearth of investigation into the functioning and participation of children with DS based on ageappropriate, socially acceptable activities. Up-to-date information is needed to guide parents and professionals with regard to reasonable expectations.

Attention deficit hyperactivity disorder (ADHD), characterized by symptoms of inattention, with or without impulsivity and hyperactivity, (Barkley, 1997; Biederman \& Faraone, 2005 DSM - fourth edition, 2000; Furman 2005) is estimated to affect between 6-12\% of typically developing school age children worldwide (Biederman \& Faraone, 2005). In typically developing populations, ADHD is more commonly diagnosed amongst boys than girls; (Bauermeister et al., 2007; Biederman et al., 2005; Biederman \& Faraone, 2005; Furman, 2005; Stefanatos \& Baron, 2007). In clinical samples, boys are six to ten times more likely to be referred and three to four times more likely to be diagnosed with ADHD (Biederman et al., 2005; Stefanatos \& Baron, 2007) while in non-referred samples, gender differences have been reported to be in the range of 1:1 to 1:3 (Biederman et al., 2005; Stefanatos \& Baron, 2007).

Children with Down syndrome, due to their intellectual disabilities may have an increased risk for ADHD behaviors over and above that associated with their developmental delays, (Hastings et al, 2005) and clinically, attention function and hyperactive behaviors are commonly reported to be problem areas for children with DS (Brown et al., 2003). However, an investigation into the literature reveals a lack of information regarding the frequency and characteristics of these deficits in this population at different ages, (Määttä, et al, 2006) as well as no data on possible gender differences in these deficits. Children with DS are not exempt from having a dual-diagnosis with ADHD (Capone et al, 2006) and, indeed, the risk of "diagnostic overshadowing" (Reiss et al, 1982) is apparent in this population. Since attention deficits are not inherently incorporated into the phenotype of individuals with MR, (Burack et al, 2001) it is important to investigate the frequency and types of attention deficits/hyperactivity amongst children with DS.

As it is now essential to adopt a holistic approach when assessing the individual especially the mentally retarded, ADHD being a commonly reported deficit can not be overlooked when assessing children with DS. Accurate information regarding the frequency of a dualdiagnosis such as ADHD amongst children with DS is important since the symptoms of this diagnosis are not inextricably linked with the cognitive impairment characteristic of DS and as such could potentially be treated under a medical model (Capone et al., 2006). The alleviation of attention deficit behaviors has the potential of improving the effectiveness of intervention for children with DS and, as a result, lead to improved function and quality of life.

Despite the limited information available, (Brown et al., 2003; Hastings et al., 2005) it was hypothesized that children with DS would show attention deficit/hyperactive behaviors at a higher frequency than that noted in typically developing populations, and that these deficits would be more common amongst older children. In addition, (based on the fact that it was a non-referred sample), it was hypothesized that no gender differences in the frequency of these deficits would be found. Finally, it was assumed that the severity of attention deficit/hyperactive behaviors would be correlated with the child's adaptive behavior and IQ. 
In our study we assessed the developmental profile of 60 children with Down syndrome between the ages of 6 and 16 years who had received a holistic early intervention program from birth until their entry into an appropriate educational framework. A focus was placed on investigating the frequency of attention deficit/hyperactive behaviors amongst these children and to assess whether it differs between sexes and whether it changes across age groups. The influence of the severity of attention deficit/hyperactive behaviors on adaptive behavior and their correlation with the child's intelligence quotient (IQ) was investigated The relationship between body function variables and participation as well as the performance of specific school-related activities was also studied.

\section{Method}

\subsection{Sample}

This study included 60 Hebrew-speaking children (33 males, 27 females) with Down syndrome, all of whom were treated at the Jerusalem Institute for Child and Family Development of the Israel Ministry of Health from birth until their entry into an appropriate special educational framework between the ages of 3 and 4 years. The children were between the ages of 5 years 10 months and 15 years 8 months (mean 9y 3mo; SD 28.8mo) at the time of testing. No child was receiving treatment at the Institute at the time of the study. The children were divided into the following three similarly sized age groups: youngest ( $n=20 ; 12$ males, eight females; mean age 6y 11mo, SD 7.1mo; range 5y 10mo-7y 8mo); middle ( $n=21$; nine males, 12 females; mean age 9y, SD 9.9mo; range 7y 9mo-10y) and oldest $(n=19 ; 12$ males seven females; mean age 12 y 2 mo, SD $20.3 \mathrm{mo}$; range $10 \mathrm{y} 2 \mathrm{mo}-15 \mathrm{y} 8 \mathrm{mo})$. These age groups were selected since it seems feasible to expect greater differences between groups of children between the ages of 6-8 (younger pre-teens) and 8-10 (older pre-teens) as compared to teenagers.

\subsection{Instruments}

\section{Psycho-social intake questionnaire}

A non-standardized measure developed by the Jerusalem Institute for Child and Family Development for internal use, completed by caregiver interview. This questionnaire provided demographic information including gender, age and whether the child received medication for attention deficits (methylphenidate) at the time of testing or in the past.

\section{ADHD Rating scale for parents and teachers (Pelham et al, 1992)}

Parents and teachers both completed the Parent-Teacher ADHD Rating Scale based on the DSM-III-R criteria (American Psychiatric Association, 1987) as described by Pelham et al. (1992). The questionnaire includes 14 items, for which the informant responds on a scale of $0-3$, resulting in a maximum score of 42 . For each informant (parent and teacher) the total score was calculated, with higher scores indicating greater difficulties. A cut-off score above 15 was used to suggest attention deficit and hyperactive behavior with scores of 21 and above suggestive of more pronounced difficulties.

\section{Vineland Adaptive Behavior Scales, interview edition (VABS) (Sparrow, et al, 1984)}

A 577-item norm-referenced and standardized parent/caregiver interview measuring personal and social skills and intended for use in populations from birth to 18 11/12 years. Standard scores are measured (in normative populations, $M=100$ and SD=15). Reliability has 
been demonstrated using internal consistency (split half means for Domains .91 to .95; for Adaptive Behavior Composite .97). In the current study, composite scores were attained for three domains (communication skills, daily living skills and socialization skills).

Stanford-Binet Intelligence Scale, fourth edition (SBIS)(Thorndike, et al, 1986)

A reliable and valid measure developed to test cognitive ability in individuals from 2 years23 years, administered by a psychologist, provided an IQ score. In normative populations, the general score has a mean of 100 and SD of 16 while subtests have a mean of 50 and a SD of 8 . The Brief IQ including the verbal reasoning, abstract/visual reasoning, quantitative reasoning and short-term memory scales were used in the current study.

\subsection{Procedure}

This study was performed as part of a larger study (Rihtman et al., 2009) and was approved by the ethics committee of the School of Occupational Therapy, Hebrew University Hadassah Medical School, Jerusalem. Letters were sent to the parents of all the children born with Down syndrome in the Jerusalem vicinity between 1988-1998 who were treated with a standard intervention protocol at the Jerusalem Institute for Child and Family Development of the Israel Ministry of Health ( $\mathrm{N}=119)$. Eight children had passed away, 30 children were not traced and 21 declined to participate, leaving the study group with 60 children. Parents signed a consent form and all participants were invited to the Institute for a testing session. A written summary was sent to the parents of each participant.

\subsection{Statistical analysis}

A Type 1 error rate of 0.05 was used for all analyses. Statistical Package for Social Sciences 13 (SPSS 13) for Windows was used for all calculations. Descriptive statistics were used to reveal the frequency of attention deficit/hyperactive behaviors. One-way ANOVA's were performed to assess age-group differences and independent sample t-tests were performed to assess gender differences on parent and teacher reports of attention deficit/hyperactive behaviors. Chi square tests were used to assess age group and gender differences on medication for attention deficit/hyperactive behaviors. Independent sample t-tests were performed to assess parent and teacher report ADHD Rating Scale score group differences in adaptive behavior. Pearson coefficient correlations were calculated to assess the correlations between parent and teacher ADHD Rating Scale scores and adaptive behaviors. One-way MANOVA's were employed to assess ADHD Rating Scale score group differences and the Stanford Binet subscales. Effect sizes were ascertained by means of Eta squared, which reflects the proportion of the total variance attributed to or accounted for by an effect, with 0.01 reflecting a small effect size, 0.06 reflecting a medium effect size and 0.14 reflecting a large effect size (Cohen 1988; Hays 1994).

\section{Results}

\subsection{Frequency of attention deficit/hyperactive behaviors}

Reports of attention deficit/hyperactive behaviors were initially considered in individual settings (home or school). Based on parent report on the ADHD Rating Scale (Figure 1), for the total group, $28.8 \%$ attained scores of 16 and above, indicative of deficits, with $11.9 \%$ attaining scores of 21 and above, indicative of more pronounced deficits. Amongst boys, $34.4 \%$ attained scores of 16 and above, while $15.6 \%$ attained scores of 21 and above. 
Amongst girls, 22.2\% attained scores of 16 and above, while $7.4 \%$ attained scores of 21 and above.

Based on teacher's report on the ADHD Rating Scale (Figure 1), for the total group, 25.6\% attained scores of 16 and above, with $9.3 \%$ attaining scores of 21 and above. Amongst boys, $32.0 \%$ attained scores of 16 and above, while $8.0 \%$ attained scores of 21 and above. Amongst girls, $16.7 \%$ attained scores of 16 and above, while $11.1 \%$ attained scores of 21 and above.

When the frequencies of attention deficit/hyperactive behaviors were considered based on parent and teacher reports combined (Figure 1), within the total group, 11.9\% attained scores of 16 and above in two settings, with $4.8 \%$ attaining scores of 21 and above in both settings. Amongst boys, $12.5 \%$ attained scores of 16 and above in two settings, with none attaining scores of 21 and above. Amongst girls, none attained scores of 16 and above in two settings, but $10.5 \%$ attained scores of 21 and above.

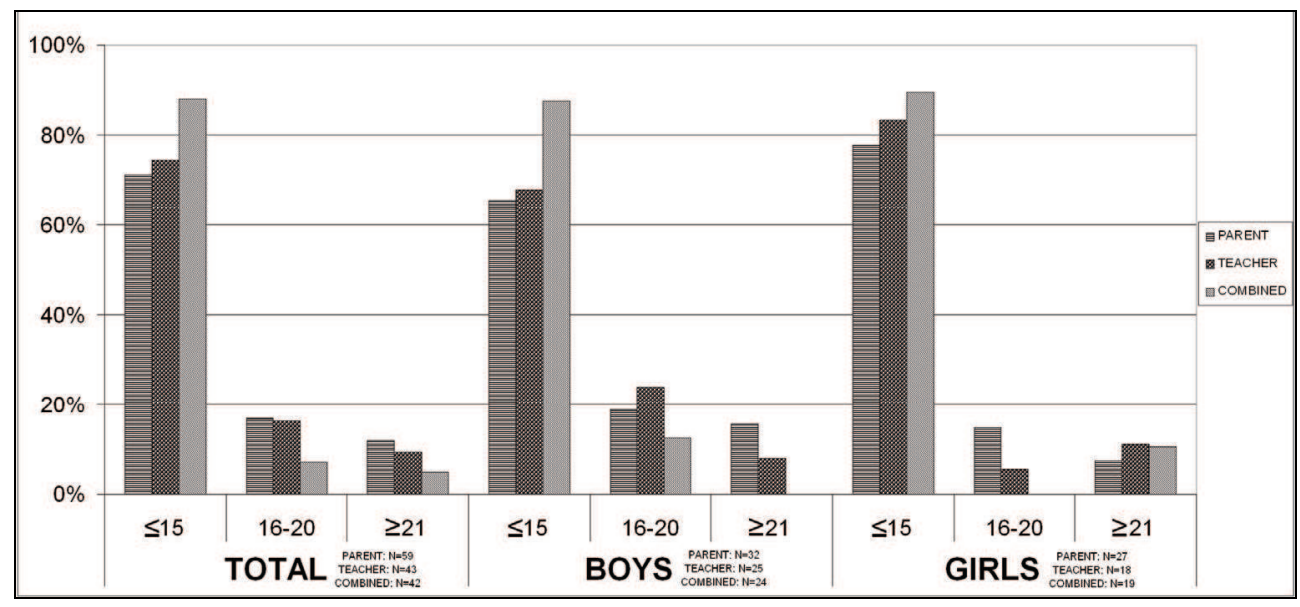

Fig. 1. ADHD Rating Scale Parent, Teacher and Combined Reports: Frequencies of attention deficit/hyperactive behaviors based on parent report, teacher report and parent and teacher report combined.

The frequencies of whether the child had never been medicated for attention deficit/hyperactive behaviors, had been medicated in the past or was medicated at the time of the study, by gender, are presented in Table 1 In order to shed light on the frequency of children with Down syndrome who had ever had behaviors warranting medication for attention deficit/hyperactive behaviors, both the children who had been medicated in the past and those who were medicated at the time of the study (past/present) were included. Of the total study population, $11.7 \%$ had been medicated for attention deficit/hyperactive behaviors at some time (present/past). Amongst the boys, 15.2\% had received medication at some time, as opposed to $7.4 \%$ of the girls.

The frequency of medication use was also considered based on the severity of reported attention deficit/hyperactive behaviors for the total study sample. Based on parent report, 9.52\% of children with ADHD Rating Scale scores of 15 and below, were medicated at some time (past/present), while this was true for 30\% of those who attained scores between 16 and 20; none of the children with scores of 21 and above were medicated (past/present). Of 
those children who attained ADHD Rating Scale scores of 15 and below based on teacher report, $12.5 \%$ were medicated or had been medicated at some time, while $14.3 \%$ of those who attained score between 16 and 20 were medicated (past/present). Again, none of the children with scores of 21 and above were medicated or had been medicated in the past (Table 1).

\begin{tabular}{|c|c|c|c|c|c|c|}
\hline & & $\begin{array}{c}\text { Boys } \\
N=33\end{array}$ & $\begin{array}{l}\text { Girls } \\
N=27\end{array}$ & $\begin{array}{l}\text { Total } \\
\mathrm{N}=60\end{array}$ & $\begin{array}{l}\text { Parent } \\
(\mathrm{N}=59)\end{array}$ & $\begin{array}{l}\text { Teacher } \\
(\mathrm{N}=43)\end{array}$ \\
\hline $\begin{array}{c}\text { Never } \\
\text { Medicated }\end{array}$ & & $\begin{array}{c}28 \\
(84.8 \%)\end{array}$ & $\begin{array}{c}25 \\
(92.6 \%)\end{array}$ & $\begin{array}{c}53 \\
(88.3 \%)\end{array}$ & - & - \\
\hline $\begin{array}{l}\text { Medicated } \\
\text { in Past }\end{array}$ & & $2(6.1 \%)$ & $1(3.7 \%)$ & $3(5.0 \%)$ & - & - \\
\hline $\begin{array}{l}\text { Medicated } \\
\text { at Time of } \\
\text { Study } \\
\text { Total }\end{array}$ & & $3(9.1 \%)$ & $1(3.7 \%)$ & $4(6.7 \%)$ & - & - \\
\hline $\begin{array}{l}\text { Medicated } \\
\text { at Some } \\
\text { Time }\end{array}$ & & $\begin{array}{c}5 \\
(15.2 \%)\end{array}$ & $2(7.4 \%)$ & $\begin{array}{c}7 \\
(11.7 \%)\end{array}$ & - & - \\
\hline \multirow{3}{*}{$\begin{array}{c}\text { ADHD } \\
\text { Rating Scale } \\
\text { Score } \\
\text { Group }\end{array}$} & $\leq 15$ & - & - & - & $\begin{array}{c}\mathrm{N}=42 \\
\text { Medicated }^{*}=4 \\
(9.5 \%)\end{array}$ & $\begin{array}{c}\mathrm{N}=32 \\
\text { Medicated }^{*}=4 \\
(12.5 \%)\end{array}$ \\
\hline & $\begin{array}{l}16- \\
20\end{array}$ & - & - & - & $\begin{array}{c}\mathrm{N}=10 \\
\text { Medicated }^{*}=3 \\
(30 \%)\end{array}$ & $\begin{array}{c}\mathrm{N}=7 \\
\text { Medicated }^{*}=1 \\
(14.3 \%)\end{array}$ \\
\hline & $\geq 21$ & - & - & - & $\begin{array}{c}\mathrm{N}=7 \\
\text { Medicated }^{*}=0 \\
(0 \%)\end{array}$ & $\begin{array}{c}\mathrm{N}=4 \\
\text { Medicated }^{*}=0 \\
(0 \%)\end{array}$ \\
\hline
\end{tabular}

*At the time of the study or in the past

Table 1. Frequencies of medication use for attention deficit/hyperactive behaviors, by gender, and by severity of these behaviors based on parent and teacher report

ANOVA's performed to investigate age group differences in parent report total ADHD Rating Scale score (Table 2) revealed no group differences, however significant differences between age groups on the teacher's report of total ADHD Rating Scale score were found, with a large effect size $\left(\mathrm{F}(2,41)=3.84, \mathrm{p}=0.030, \mathrm{\eta}^{2}=0.16\right)$. A Scheffe post-hoc analysis was performed to assess this result; the oldest group had a significantly higher score on the ADHD Rating Scale teacher report $(M=13.63 ; S D=7.70)$ than the youngest group $(M=6.79$; $\mathrm{SD}=4.17 ; \mathrm{p}=0.030)$ but the middle group had an intermediate score $(\mathrm{M}=10.89 ; \mathrm{SD}=8.87)$ that did not differ significantly from the oldest or youngest groups. There were no significant gender differences on the ADHD rating scales between boys and girls.

To analyze age-group differences in the need for medication for attention deficit/hyperactive behaviors, only those children who were medicated at the time of the study were included in the analysis (Table 1) as the inclusion of those who had been medicated in the past may have skewed the results. A chi ${ }^{2}$ test performed to assess age group differences in whether the child received medication for attention 
deficit/hyperactivity behaviors at the time of the study revealed no group differences $\left(\chi^{2}[2\right.$, $\mathrm{N}=60]=0.43, \mathrm{p}=0.81$, not significant).

Independent sample t-tests performed to assess gender differences on parent report total ADHD Rating Scale score and teacher report total ADHD Rating Scale score, revealed no significant differences (Table 2). No gender differences in whether the child received medication for attention deficit/hyperactivity behaviors at the time of the study were revealed using a chi ${ }^{2}$ test $\left(\chi^{2}[1, N=60]=0.69, p=0.40\right.$, not significant $)$.

\begin{tabular}{llllllllll}
\hline & $\begin{array}{c}\text { Youngest } \\
\mathrm{M}(\mathrm{SD})\end{array}$ & $\begin{array}{c}\text { Middle } \\
\mathrm{M}(\mathrm{SD})\end{array}$ & $\begin{array}{c}\text { Oldest } \\
\mathrm{M}(\mathrm{SD})\end{array}$ & $\begin{array}{c}\text { Boys Total } \\
\text { Score } \\
\mathrm{M}(\mathrm{SD})\end{array}$ & $\begin{array}{c}\text { Girls Total } \\
\text { Score } \mathrm{M} \\
(\mathrm{SD})\end{array}$ \\
\hline $\begin{array}{l}\text { Parent } \\
\text { report }\end{array}$ & $\mathrm{n}=20$ & $\mathrm{n}=18$ & $\mathrm{n}=21$ & $\mathrm{df}$ & $\mathrm{p}$ \\
$\begin{array}{l}\text { Teacher } \\
\text { report }\end{array}$ & $\mathrm{n}=15$ & $\mathrm{n}=9$ & $\mathrm{n}=19$ & $14.22(5.03)$ & $12.33(8.45)$ & 1.06 & 57 & $0.29(\mathrm{NS})$ \\
\hline
\end{tabular}

Table 2. Average parent and teacher ADHD Rating Scale score by age group and independent sample t-tests to assess gender differences based on parent report and teacher report total ADHD Rating Scale score

\subsection{ADHD Rating scale score group differences in measures of adaptive behavior}

The results of independent sample t-tests performed to assess the differences between parent report ADHD Rating Scale score groups (15 and below; 16 and above) on the subscores of the three Vineland Adaptive Behavior Scale (VABS) domains (communication skills, daily living skills and socialization skills) are presented in Table 3. A significant difference with a medium effect size was found on the daily living skills standard score $(\mathrm{t}[57]=2.03 ; \mathrm{p}=0.047)$ and a significant difference with a medium-to-large effect size was found on the communication skills standard score $(\mathrm{t}[56]=2.58 ; \mathrm{p}=0.013)$..

Independent sample t-tests performed to assess the differences between teacher report ADHD Rating Scale score groups (15 and below; 16 and above) on the sub-scores of the three VABS domains (communication skills, daily living skills and socialization skills) revealed no group differences (Table 3). Due to the discrepancy between parent and teacher report in terms of adaptive behavior, we applied Pearson Coefficient correlations between the parent and teacher ADHD Rating Scale total scores. Results yielded only moderate significant correlations $(\mathrm{r}=0.46 ; \mathrm{p}=<0.01)$.

\subsection{Correlations between parent and teacher ADHD rating scale scores and adaptive behaviors}

Pearson Coefficient correlations between the VABS and parent report total ADHD Rating Scale score revealed significant moderate correlations for the communication skills standard score $(\mathrm{r}=-0.38)$ and the daily living skills standard score $(\mathrm{r}=-0.37)$ but not for the socialization skills standard score. Pearson Coefficient correlations between the VABS and teacher report total ADHD Rating Scale score revealed no significant correlations (Table 3). 


\begin{tabular}{|c|c|c|c|c|c|c|c|}
\hline Measure & Informant & Group & Mean(SD) & t-test & $\eta^{2}$ & $\mathrm{r}$ & $\mathrm{CI}$ \\
\hline \multirow{2}{*}{$\begin{array}{l}\text { Communicati } \\
\text { on Skills } \\
\text { Standard } \\
\text { Score }\end{array}$} & Parent & $\begin{array}{l}\leq 15 \\
\geq 16\end{array}$ & $\begin{array}{l}54.02(11.64) \\
45.53(10.81)\end{array}$ & $\begin{array}{c}\mathrm{t}[56]=2.58 \\
\mathrm{p}=0.013^{*}\end{array}$ & 0.11 & $\begin{array}{c}-0.38 \\
p=0.003^{*}\end{array}$ & {$[-0.58]-[-0.13]$} \\
\hline & Teacher & $\begin{array}{l}\leq 15 \\
\geq 16\end{array}$ & $\begin{array}{l}53.19(11.00) \\
51.10(16.47)\end{array}$ & $\begin{array}{c}\mathrm{t}[40]=0.46 \\
\mathrm{p}=0.65\end{array}$ & $\mathrm{~N} / \mathrm{A}$ & $\begin{array}{c}-0.24 \\
p=0.131\end{array}$ & {$[-0.50]-[0.07]$} \\
\hline \multirow{2}{*}{$\begin{array}{l}\text { Daily Living } \\
\text { Skills } \\
\text { Standard } \\
\text { Score }\end{array}$} & Parent & $\begin{array}{l}\leq 15 \\
\geq 16\end{array}$ & $\begin{array}{l}50.38(14.64) \\
41.71(15.50)\end{array}$ & $\begin{array}{c}\mathrm{t}[57]=2.03 \\
\mathrm{p}=0.047^{*}\end{array}$ & 0.07 & $\begin{array}{c}-0.37 \\
p=0.004^{*}\end{array}$ & {$[-0.57]-[-0.13]$} \\
\hline & Teacher & $\begin{array}{l}\leq 15 \\
\geq 16\end{array}$ & $51.06(15.14)$ & $\begin{array}{c}\mathrm{t}[41]=1.09 \\
\mathrm{p}=0.28\end{array}$ & $\mathrm{~N} / \mathrm{A}$ & $\begin{array}{c}-0.25 \\
p=0.107\end{array}$ & {$[-0.51]-[0.06]$} \\
\hline \multirow{2}{*}{$\begin{array}{l}\text { Socialization } \\
\text { Skills } \\
\text { Standard } \\
\text { Score }\end{array}$} & Parent & $\begin{array}{l}\leq 15 \\
\geq 16\end{array}$ & $56.74(15.15)$ & $\begin{array}{c}\mathrm{t}[52]=0.54 \\
\mathrm{p}=0.474\end{array}$ & $\mathrm{~N} / \mathrm{A}$ & $\begin{array}{c}-0.21 \\
p=0.124\end{array}$ & {$[-0.45]-[-0.06]$} \\
\hline & Teacher & $\begin{array}{l}\leq 15 \\
\geq 16\end{array}$ & $\begin{array}{l}56.14(12.44) \\
59.00(20.91)\end{array}$ & $\begin{array}{c}\mathrm{t}[37]=-0.53 \\
\mathrm{p}=0.60\end{array}$ & $\mathrm{~N} / \mathrm{A}$ & $\begin{array}{c}-0.04 \\
p=0.822\end{array}$ & {$[-0.35]-[0.28]$} \\
\hline
\end{tabular}

*Statistically significant, $\mathrm{P}<, 0.05 ; \mathrm{CI}$ confidence interval

Table 3. Independent sample t-tests between ADHD Rating Scale score groups (parent and teacher; 15 and below; 16 and above) and subscales of the Vineland Adaptive Behavior Scales and Pearson Coefficient correlations between total ADHD Rating Scale scores (parent and teacher) and the standard scores of the Vineland Adaptive Behavior Scales:

\subsection{IQ differences based on parent and teacher ADHD rating scale score groups}

The cognitive profile of the study sample has been previously reported (Rihtman et al., 2009). In the current study, the IQ scores were compared between children identified as having attention deficit/hyperactive behaviors and those without. One-way MANOVA's were employed to assess ADHD Rating Scale score group differences $(\leq 15 ; \geq 16)$ in the four Stanford Binet subscales. Based on parent report, no significant group differences were found (Wilk's $\Lambda=0.91, F(4,50)=1.29, \mathrm{p}=0.28$, NS). Likewise, no significant group differences were found based on teacher report (Wilk's $\Lambda=0.88, F(4,36)=1.26, p=0.30, N S$ ).

\section{Discussion}

A high rate of Attention Deficit Disorder (ADHD) was previously observed by us in several groups of children; among the offspring of mothers with pregestational diabetes (Ornoy et 
al, 1998), among children born to mothers with gestational diabetes (Ornoy et al, 1999), as well as among offspring of heroin dependent mothers (Ornoy et al, 2001). These and other studies emphasize the importance of environmental factors to which the developing embryo and fetus were exposed in the etiology of ADHD. This is in addition to the well known genetic etiology of ADHD (Biederman et al., 2005; Biederman \& Faraone, 2005; Furman, 2005). In the present study we were interested to assess the possible impact of DS, where trisomy 21 induces changes in many different genes, on the rate of ADHD, using accepted assessment measures.

In our previous study (Rithman et al, 2009) on the same group of children, we did not find any age related decline in the IQ scores of the children with DS. There was a significant correlation between IQ and different neurodevelpomental and adaptational measures (visual-motor integration and adaptive behavior) supporting previous findings implying that the IQ of children with Down syndrome is related to their success at implementing functional components and participating in specific activities. There was an age-related body function improvements and correlations between specific body functions and participation.. We also found sex differences on the short-term memory and motor function, with females performing better than males. However, functional sex differences on the specific VABS measures of copying, handwriting and free writing were not found. It was therefore of interest to see whether the occurrence of inattention is related to the IQ or to gender differences.

As stated above, the goals of the current study were to investigate the frequency of attention deficit/hyperactive behaviors amongst children with Down syndrome between the ages of 6 and 16, to assess age-group and gender differences in these behaviors and to analyze the relationship between the severity of these deficits and adaptive behavior and IQ. The findings have the potential of being both clinically significant as well as opening avenues for further investigation of the attentional function of children with DS.

The investigation into the frequency of attention deficit/hyperactive behaviors in this population in different settings revealed that it may be prudent to consider these behaviors from a number of perspectives. While current diagnostic criteria require deficits in two settings to warrant a diagnosis of attention deficit hyperactivity disorder (ADHD) (American Psychiatric Association, 2000), the results from the investigation of these behaviors at home and at school, as well as an analysis of combined parent and teacher reports, suggest that amongst children with DS, these behaviors should be considered from both angles. When the reports of the parent or teacher ADHD Rating Scale were considered individually, the frequency of attention deficit/hyperactive behaviors amongst children with DS appeared to be more common than that found in typically developing populations. When behavioral reports from both the child's home and educational environments were considered (as required to warrant a diagnosis of ADHD), reported deficits in the total study group were similar to that found in typically "normal" developing populations $(\sim 12 \%)$, with a similar frequency noted amongst children who had been medicated for these deficits at some time.

It may be feasible to assume that children with DS with more severe attention deficit/hyperactive behaviors reveal these deficits in both the home and educational environments and are those children whose deficits are pronounced enough to warrant medical intervention. Moreover, it should be considered that two of those children medicated for attention deficit/hyperactive behaviors at the time of the study had parent 
ADHD Rating Scale scores below 15 and three had teacher ADHD Rating Scale scores below 15. Thus, even though these children were not included within the group of children demonstrating attention deficit/hyperactive behaviors, it is feasible to assume that they were medicated due to these behaviors and the medication was responsible for the lower scores on the ADHD Rating Scale; thus, the frequency of attention deficit/hyperactive behaviors is even higher than reported. This finding implies that, based on current diagnostic criteria, ADHD is apparently more prevalent amongst children with DS than amongst typically developing children (Biederman \& Faraone, 2005).

However, the diagnostic potential of individual parent or teacher report in this population should not be overlooked. Our findings of inconsistencies between parent and teacher reports reinforce the need to consider not only whether or not the child with DS has a diagnosis of ADHD according to diagnostic criteria, but also whether the attention deficit/hyperactive behaviors may be expressed differently in different environments amongst non-referred samples in this population. The findings of reported deficits in individual environments are important to consider amongst this population, particularly when considering our findings of correlations between attentional function and adaptive behavior. Indeed, in a genetic study, Gizer et al., (2008) recently found that, while the combination of mother and teacher reports yielded the strongest association for hyperactiveimpulsive symptoms, teacher reports alone were sufficient for identifying inattentive symptoms. This finding of a discrepancy on a genetic level reinforces the point that attention deficit/hyperactive behaviors can not be overlooked in individual settings, since there may be key differences in how parents and teachers rate attention deficit/hyperactive behaviors. Moreover, varying manifestations of this disorder (for example, hyperactive as opposed to inattentive symptoms) may be identified based on reports of different deficits in diverse environments, since different environments place different demands on children. As this deficit has an important impact on adaptive functioning amongst children with DS, this warrants consideration even if there are reports of deficits in one setting alone.

In the current study, when reports of deficits in only one environment (school or home) were considered, it appeared that the frequency of these deficits may be more common $(\sim 27 \%)$ than that found in typically developing populations.. While this may not conform to a diagnosis of ADHD, this frequency warrants consideration, since these deficits appear to impact on the functioning of these children in important areas. Deficits in only one setting may reflect a less severe form of ADHD or an environment-specific form of ADHD which may be similar in its severity to non-referred samples. However, these frequencies suggest that more than a quarter of children with DS will show some form of attention deficit/hyperactive behaviors in at least one setting.

The findings of relatively high percentages of medication use within the groups of children with scores below 15 on the ADHD Rating Scale, based on both parent and teacher report, and the lack of medication use within the groups of children scoring 21 and above on the ADHD Rating Scale may not be altogether surprising. It is likely that many of the medicated children attained lower scores due to their medication use, while those who attained extreme high scores did so since they were not medicated. Moreover, it is important to bear in mind that the use of medication for attention deficit/hyperactive behaviors is also dependent on parental opinion and preferences, the age of diagnosis of attention deficit/hyperactive behaviors and the opinions of the treating physician regarding the use of these medications in young children. Thus, those children with severe manifestations of 
attention deficit/hyperactive behaviors may be un-medicated due to parental preference and not due to a lack of need.

No age-group differences in the attentional profile of the cohort were found based on parent report, yet differences were found based on teacher's report, potentially due to different demands of the different environments which shift with age. The finding of age-group differences based on teacher report is particularly noteworthy, and may shed light on a potentially shifting attentional profile within the educational environment amongst children with DS with age, due to increased academic demands. While no age differences were noted between the youngest (younger pre-teen) and middle (older pre-teen) which is intermediate in its scores between the three groups, or middle and oldest (teenage) groups, the oldest group differed significantly from the youngest group and may suggest that attention deficit/hyperactive behaviors increase gradually as children with DS become teenagers.

Since this was a non-referred sample, the investigation into gender differences seems to be of particular importance. The findings appear to conform to the opinion regarding nonreferred samples of typically developing children that gender differences are not as pronounced as in clinical samples. When both settings (i.e. parental and teacher's ADHD Rating Scale) were considered, the frequency of deficits was indeed in the realm of 1:1 (12.5\%:10.5\%; boys to girls respectively). While the differences did not reach significance, it should be noted that boys appeared to be medicated more than girls $(15.2 \%$ and $7.4 \%$ respectively), potentially due to the clinical manifestations of their difficulties. Likewise, when only one setting (home/school) was considered, boys appeared to have higher frequencies of reported difficulties $(\sim 33 \%)$ as opposed to girls $(16.7 \%$ [teacher] $-22.2 \%$ [home]) yet, again, these differences did not reach statistical significance. Once again, this reinforces the need to consider reports of attention deficit/hyperactive behaviors in both the education and home environment of the child with DS.

The investigation of adaptive functioning in light of attention deficit/hyperactive behaviors amongst children with DS sheds light on a vital area of investigation for this population. It may not be surprising that no differences were found between children above and below the cutoff point for attention deficit/hyperactive behaviors on the socialization domain of the Vineland Adaptive Behavior Scales (VABS) in either the teacher or parent report as this is known to be an inherent area of strength for individuals with DS (Fidler et al 2006) and may therefore be less influenced by attention deficit/hyperactive behaviors. However, the finding of an association between attention deficit/hyperactive behaviors based on parent report and adaptive behaviors in the realms of daily living and communication skills, with greater impairments in attentional function leading to greater adaptive behavior impairments, has immense clinical significance. It would appear that skills in these realms are more based on learning and acquired behaviors and abilities than those required for successful social functioning which is a strength of this population, regardless of the lack of an association between IQ scores and attentional function in the current study since learning and attention are associated at every level of cognitive functioning. If this were the case, since intact attentional functioning is a major component of learning, (Posner et al, 2008) this association between impairments in attention and these elements of adaptive behavior is not surprising. It is, however, important to note as this association particularly reinforces the need to consider possible treatment of attention deficit/hyperactive behaviors in this population, even if these deficits are apparent only in one setting, since learning occurs both within the school environment and outside of it. 
The lack of an association between adaptive behavior and attention deficit/hyperactive behaviors based on teacher report also raises a number of points to consider. This finding may reflect an important principle of current health paradigms, (World Health Organization, 2001) namely, that deficits in participation in different settings may not always result from deficits in body functions and structures. As such, a child with attention deficit/hyperactive behaviors in the classroom may not necessarily have participation deficits in their overall school functioning. An alternative explanation may be that, since the VABS was completed by parents while the ADHD Rating Scale was completed by teachers, the lack of an association between the VABS and the teachers ADHD Rating Scale may be due to informant differences. Indeed, only a moderate correlation between the parent and teacher report ADHD Rating Scale was found. In addition to the lack of congruence between parents and teachers with regard to the adaptive behavior of children with DS, Crystal et al (2001) stress that varying informant sources can produce significantly different descriptions of attention deficit/hyperactive behaviors. Different aspects of adaptive behavior may be stressed in different environments, and what may be considered to be adaptive behavior at home may not necessarily be perceived as such at school. It therefore seems prudent for future studies investigating the attention deficit/hyperactive profile of children with DS to assess adaptive behavior based on educator report as well.

In our previous study on the same population we assessed the functional and behavioral profile of these 60 children with Down syndrome. There were sex differences on the shortterm memory as well as motor function, with females performing better than males. It is not clear whether the developmental continuum differs between males and females, and our findings begin to shed light on such differences.

We also found previously an association between IQ and measures of visual-motor integration and adaptive behavior. This supports previous findings implying that the IQ of children with DS is related to their success at implementing functional components and participating in specific activities. This result is also important when considering reports that functional attainments earned in childhood seem to be maintained into adulthood in this population (Brown et al, 1990). Adults with Down syndrome who are the most accomplished in terms of independence in daily living and maintaining paid employment are those who participated in structured school experiences aimed at teaching them specific skills. Yet reports of an IQ plateau or decrease beginning in early adulthood are common (wang, 1996).

Children with Down syndrome who show improved performance on structured tests may be those with greater motivational levels and thus predisposed to greater adaptive functioning by virtue of having a greater tendency toward experience and learning. Alternatively, more successful adaptive functioning may occur in children with the physical foundation of better functional components. It is possible that these children are then the ones who are better able to participate successfully in functional activities. If this is true, it would lend empirical support for intervention that is directed at improving functional components while using these functions to create a bridge with actual participation in ageappropriate activities.

A number of limitations are evident in the present study. Foremost, the study sample was small and was not compared to a typically developing population. An interesting idea for further investigation would be to compare the adaptive functioning of children with ADHD 
with and without DS. In addition, the use of the Parent-Teacher ADHD Rating Scale only provides limited information and future studies would benefit from using more extensive ADHD testing. Furthermore, the age group division could have been more homogenous with larger groups. Finally, the correlations performed in this study can not necessarily be considered to reveal a causal relationship between ADHD and adaptive behavior or IQ. While the findings begin to shed light on this area, further research should apply interventional studies which may provide a clearer picture regarding causal relationships between attention deficit/hyperactive behaviors and adaptive functioning of children with DS.

An additional limitation of the study is the wide age range of the oldest group, as a result of the attempt to include all teenagers within the same group and to examine differences between younger $(6-8 y)$ and older $(8-10 y)$ pre-adolescent school-aged children. However, future studies should ensure improved homogeneity of age groups and should also attempt to attain objective measures of handwriting performance. Finally, this study applied a crosssectional study design that limits the interpretation of the developmental continuum of the child with Down syndrome. Further research should seek to apply longitudinal study designs.

\section{Conclusions}

Changing international health measures and intervention in children with developmental disorders also focuses in treating children with Down syndrome, with increased emphasis being placed on participation and on the acquisition of specific, functional skills and functional independence, all being vital element of their quality of life. Moreover, the fact that there is a high rate of ADHD among children with Down syndrome forces us to pay attention to that possibility in each child with trisomy 21 as proper medical or other treatment may help the child with Down syndrome to get better help.

Our findings of continuous improvement in function with age, if such intervention has been provided, is further evidence supporting the need for pediatric DS intervention to encourage improved body functions while emphasizing the acquisition of functional skills that enable enhanced participation in age-appropriate activities. In addition, this study raises doubts as to whether or not children with DS do indeed reach a functional plateau and offers the possibility of changing our perception with regard to the functional and educational potential of children with trisomy 21.

\section{References}

American Psychiatric Association. (1987). Diagnostic and statistical manual of mental disorders (3rd ed., Rev.). Washington, DC:

American Psychiatric Association. (2000). Diagnostic and statistical manual of mental disorders (4th ed., Text Revision). Washington, DC:

Barkley, RA. (1997). Behavioral inhibition, sustained attention, and executive functions: Constructing a unifying theory of ADHD. Psychological Bulletin, 221.,65-94.

Bauermeister, JJ, Shrout PE, Cha'vez, L, Rubio-Stipec, M, Ramı'rez, R, Padilla, L\& Canino, G. (2007). ADHD and gender: Are risks and sequela of ADHD the same for boys and girls? Journal of Child Psychology and Psychiatry, 48, 831-839. 
Biederman, J \& Faraone SV. (2005). Attention deficit hyperactivity disorder. Lancet,366, 237248.

Biederman J., Kwon A., Aleardi M., Chouinard V, Marino T., Cole, H.\&, Faraone SV. (2005). Absence of gender effects on attention deficit hyperactivity disorder: Findings in non referred subjects. American Journal of Psychiatry, 162, 1083-1089.

Bittles, A H, \& Glasson, E J. (2004). Clinical, social and ethical implications of changing life expectancy in Down syndrome. Developmental Medicine E Child Neurology, 46, 282286.

Brown FR, Greer MK, Aylward EH, Hunt HH. (1990). Intellectual and adaptive functioning in individuals

with Down syndrome in relation to age and environmental placement. Pediatrics 85,450 452.

Brown, JH, Johnson MH, Paterson, SJ, Gilmore, R, Longhi, E, \& Karmiloff-Smith A. (2003). Spatial representation and attention in toddlers with Williams syndrome and Down syndrome. Neuropsychologia, 41, 1037-1046.

Burack J A,, Evans, DW, Klaiman, C \& Iarocci, G. (2001). The mysterious myth of attention deficits and other defect stories: Contemporary issues in the developmental approach to mental retardation. International Review of Research in Mental Retardation, 24, 299-320.

Capone, G, Goyal, P, Ares, W \& Lannigan, E. (2006). Neurobehavioral disorders in children, adolescents, and young adults with Down syndrome. American Journal of Medical Genetics, Part C, 142C, 158-172.

Carr J (2003). Patterns of aging in 30-35-year olds with Down's syndrome. J Appl Res Intellect $16,29-40$.

Cohen, J. (1988). Statistical power analysis for the behavioral sciences ( $2^{\text {nd }}$ ed.). Hillsdale, NJ: Erlbaum.

Crystal, DS, Ostrander, R, Chen, RS, \& August, GJ. (2001). Multimethod assessment of psychopathology among DSM-IV subtypes of children with attention-deficit/ hyperactivity disorder: Self-, parent, and teacher Reports. Journal of Abnormal Child Psychology, 29, 189-205.

Fidler, D J., Hepburn, S, \& Rogers, S. (2006). Early learning and adaptive behavior in toddlers with Down syndrome: Evidence for an emerging behavioral phenotype? Down's Syndrome, Research and Practice, 9, 37-44.

Furman, L. (2005). What is attention-deficit hyperactivity disorder (ADHD)? Journal of Child Neurology, 20, 994-1002.

Gizer, IR, Waldman ID, Abramowitz A, Barr CL, Feng Y, Wigg KG, Misener VL, \& Rowe DC. (2008). Relations between multi-informant assessments of ADHD symptoms, DAT1, and DRD4. Journal of Abnormal Psychology, 117, 869-880.

Hanson MJ. (2003). Twenty-five years after early intervention: A follow-up of children with Down syndrome and their families. Infants and Young Children, 16, 354-365.

Hastings RP, Beck A., Daley, D \& Hill C. (2005). Symptoms of ADHD and their correlates in children with intellectual disabilities. Research in Developmental Disabilities, 26, 456468 .

Hays WL.(1994). Statistics. 5th edn. Belmont, CA: Wadsworth. 
Määttä, T, Tervo-Määttä, T, Taanila, A, Kaski, M, \& Iivanainen, M. (2006). Mental health, behaviour and intellectual abilities of people with Down syndrome. Down's Syndrome, Research and Practice, 11, 37-43.

Menkes, JH, \& Falk,RE. (2005). Chromosomal anomalies and continuous-gene syndromes. In J. H. Menkes, H. B. Sarnat, \& B. L. Maria (Eds.), Child Neurology, $7^{\text {th }}$ Ed. (pp. 227257). Philadelphia, PA: Lippincott Williams and Wilkins.

Ornoy, A, Ratzon, N, Greenbaum, C, Peretz E, Soriano D \& Dulitzky M. (1998). Neurobehavior of children born to diabetic mothers a early school age. Arch Dis Chil 79, F94-F99.

Ornoy, A. Wolf, A., Ratzon, N., Greenbaum, C \& Dulitzky, M. (1999). neurodevelopmental impact of diabetic alterations on early school-age children born to mothers with Gestational Diabetes. Arch. Dis. Child, 81, F10-F14.

Ornoy A, Segal J, Bar-Hamburger R \& Greenbaum, C. (2001). The developmental outcome of school age children born to heroin- dependent mothers: Importance of environmental factors. Dev. Med. Child. Neurol. 43, 668-675.

Pelham, W.E, Gangy, E M, Greenslade, KE, \& Milich, R. (1992). Teacher ratings of DSM-III-R symptoms for the disruptive behavior disorders. Journal of the American Academy of Child and Adolescent Psychiatry, 31, 210-218.

Posner, MI, Rothbart, MK, \& Rosario Rueda, M. (2008). Brain mechanisms and learning of high-level skills. In A. M. Battro, K. W. Fischer, \& P. J. Léna (Eds.), The educated brain: Essays in neuroeducation. Cambridge, UK: Cambridge University Press pp. 151-165.

Reiss, S., Levitan, G. W., \& Szyskzo, J. (1982). Emotional disturbances and mental retardation: Diagnostic overshadowing. American Journal of Mental Deficienty, 86, 567-574.

Rihtman, T., Tekuzener, E., Parush, S., Tenenbaum, A., Bachrach, S.J., \& Ornoy, A. (2009). Are the cognitive functions of children with Down syndrome related to their participation? Developmental Medicine \& Child Neurology, 52, 72-78.

Roubertoux P\& Kerdelhue B (2006). Trisomy 21: from chromosomes to mental retardation. Behav Genet; 36, 346-54.

Sparrow, SS, Balla, DA \& Cicchetti DV. (1984). Vineland Adaptive Behavior Scales interview edition: Expanded form manual. Minnesota, MO: American Guidance Service.

Stefanatos, GA, \& Baron, IS. (2007). Attention-deficit/hyperactivity disorder: A neuropsychological perspective towards DSM-V. Neuropsychology Review, 17, 5-38.

Thorndike, RL, Hagen, EP, \& Sattler, J. M. (1986). The Stanford Binet Intelligence Scale, Fourth Edition: Guide for administering and scoring. Chicago, IL: Riverside Publishing.

Turner, S \& Alborz, A. Academic attainments of children with Down's syndrome: a longitudinal study. Br J Educ Psychol 2003; 73: 563-83.

Van Cleve, SN \& Cohen WI. (2006). Part I: Clinical practice guidelines for children with Down syndrome from birth to 12 years. Journal of Pediatric Health Care, 20(1), 47-54.

Vicari, S. (2006). Motor development and neuropsychological patterns in persons with Down syndrome. Behavior Genetics, 36, 355-364.

Vicari S \& Carlesimo GA (2006). Short-term memory deficits are not uniform in Down and Williams syndromes. Neuropsychol Rev 2006; 16: 87-94. 
Wang PP. (1996). A neuropsychological profile of Down syndrome: cognitive skills and brain morphology. Ment Retard Dev Disabil Res Rev 2, 102-108

World Health Organization. (2001). International Classification of Functioning, Disability and Health. Geneva: 


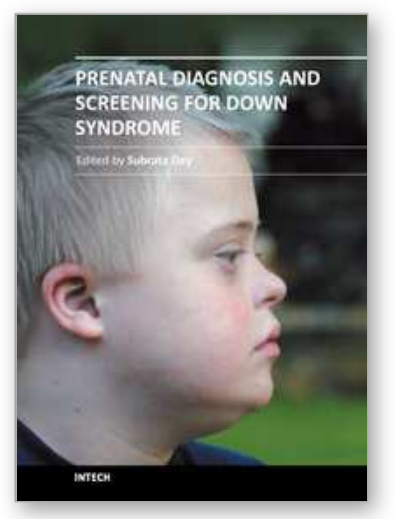

\author{
Prenatal Diagnosis and Screening for Down Syndrome \\ Edited by Prof. Subrata Dey
}

ISBN 978-953-307-355-2

Hard cover, 232 pages

Publisher InTech

Published online 17, August, 2011

Published in print edition August, 2011

This book provides a concise yet comprehensive source of current information on Down syndrome. Research workers, scientists, medical graduates and paediatricians will find it an excellent source for reference and review. This book focuses on exciting areas of research on prenatal diagnosis - Down syndrome screening after assisted reproduction techniques, noninvasive techniques, genetic counselling and ethical issues. Whilst aimed primarily at research worker on Down syndrome, we hope that the appeal of this book will extend beyond the narrow confines of academic interest and be of interest to a wider audience, especially parents and relatives of Down syndrome patients.

\title{
How to reference
}

In order to correctly reference this scholarly work, feel free to copy and paste the following:

Asher Ornoy, Tanya Rihtman and Shula Parush (2011). Adaptive and Behavioral Development in Children with Down Syndrome at School Age with Special Emphasis on Attention Deficit Hyperactivity Disorder (ADHD), Prenatal Diagnosis and Screening for Down Syndrome, Prof. Subrata Dey (Ed.), ISBN: 978-953-307-355-2, InTech, Available from: http://www.intechopen.com/books/prenatal-diagnosis-and-screening-for-downsyndrome/adaptive-and-behavioral-development-in-children-with-down-syndrome-at-school-age-with-specialemphas

\section{INTECH}

open science | open minds

\author{
InTech Europe \\ University Campus STeP Ri \\ Slavka Krautzeka 83/A \\ 51000 Rijeka, Croatia \\ Phone: +385 (51) 770447 \\ Fax: +385 (51) 686166 \\ www.intechopen.com
}

\author{
InTech China \\ Unit 405, Office Block, Hotel Equatorial Shanghai \\ No.65, Yan An Road (West), Shanghai, 200040, China \\ 中国上海市延安西路65号上海国际贵都大饭店办公楼 405 单元 \\ Phone: +86-21-62489820 \\ Fax: +86-21-62489821
}


(C) 2011 The Author(s). Licensee IntechOpen. This chapter is distributed under the terms of the Creative Commons Attribution-NonCommercialShareAlike-3.0 License, which permits use, distribution and reproduction for non-commercial purposes, provided the original is properly cited and derivative works building on this content are distributed under the same license. 